\title{
Research of Low Explosion Pressure and Low Fuel Consumption for Double-Wall-Jet Combustion System of DI Engine
}

\author{
Pengjiang Guo ${ }^{1, *}$ and Xiyan $\mathrm{Gao}^{2}$ \\ 1,* School of Transportation and Vehicle Engineering, Shandong University of Technology, Zibo, China \\ ${ }^{2}$ Internal Combustion Engine Research Institute, Dalian University of Technology, Dalian, China \\ ${ }^{*}$ Corresponding author
}

\begin{abstract}
According to the spray characteristics and formation mechanism of NOx and soot of DI engine, a double-wall-jet combustion system of low compression ratio is designed and related experimental research is carried out. The results show that: The instantaneous heat release rate of double-wall-jet combustion system shows a trend of single peak. When the compression ratio is reduced, the starting point of combustion is postponed for about $2 \sim 3{ }^{\circ} \mathrm{CA}$, which makes the cylinder pressure greatly reduced, the cylinder combustion temperature and NOx emissions reduced ensuring the dynamic performance of the engine. The fuel consumption rate characteristics is analyzed according to the cumulative heat release rate, the percentage of total heat release, the single peak heat release rate and the indicated thermal efficiency, it shows that the fuel consumption rate is at a very low level. To reflect the advantages of the doublewall-jet combustion system, the combustion phase of the doublewall-jet engine is consistent with that of the original one, the fuel supply time is postponed for $2^{\circ} \mathrm{CA}$. The fuel consumption rate of the double-wall-jet engine is equivalence to that of the original one, the peak cylinder pressure and emissions of NOx is lower.
\end{abstract}

Keywords- heat release rate; double-wall-jet; diesel;Nox; indicated thermal efficiency

\section{INTRODUCTION}

A new type of double-wall-jet combustion system for diesel engine is designed ${ }^{[1,2,3,4]}$. The so-called double-wall-jet combustion system means: there are directing arc and small steps on the inner surface of the combustion chamber wall, the liquid spray injected by porous injector hits on the inner surface of the combustion chamber wall, and reflected by the directing arc and the small steps, so the layered spray is achieved. Schematic diagram of the combustion chamber and mixture formation are shown in Figure 1.

The double-wall-jet combustion system is based on the ideas of wall-guiding-spray, stratification and space distributed, so the goal of low-emission can be achieved.

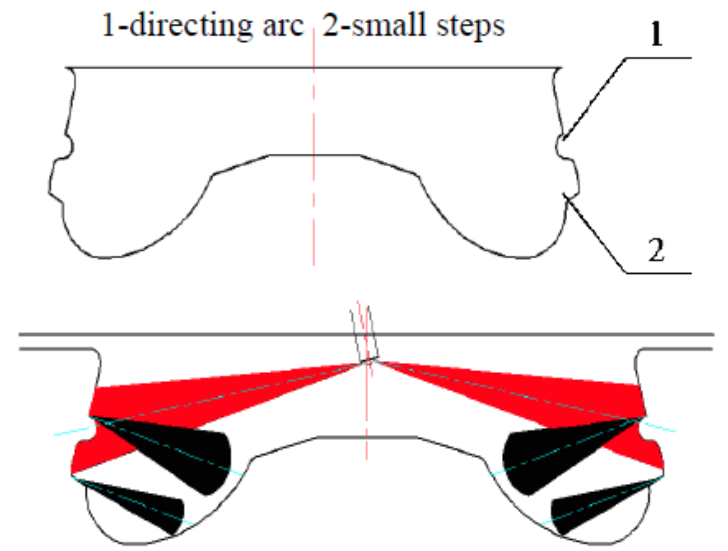

FIGURE I. SCHEMATIC DIAGRAM OF THE DOUBLE-WALLJET COMBUSTION CHAMBER AND MIXTURE FORMATION

According to the single peak heat release rate characteristics of the double-wall-jet combustion system, and combining the ideas of rapid combustion, the test research of low compression ratio and low explosion pressure for the double-wall-jet combustion system of DI engine is carried out holding the power in constant. The benefits of low explosion pressure are discussed; the tested results show that low fuel consumption can also be achieved.

\section{TeSt DeVICE AND MethoD}

The combustion characteristics and influencing factors of distributed space Double-Wall-Jet combustion systems are tested and researched, the specific engine parameters are shown in Table 1. The whole test is carried out on the engine bench, the test equipments and instruments are: Qidong DW250 electric eddy current dynamometer, FGA-4100 vehicle emission analyzer, FBY-3 Bosch smoke meter, AVL Indiset 620 combustion analyzer. The researched double-wall-jet combustion system is on the basis of the original engine, the shape of the combustion chamber is shown in Figure 1. The geometric compression ratio is 16.5 , the injector is of 6 holes, $0.21 \mathrm{~mm}$ pore diameter, and $158^{\circ}$ nozzle angle. The injection pressure and injection timing is same as the original engine. The static injection timing is $12^{\circ} \mathrm{CA}$ BTDC, the airway swirl ratio is consistent with the original engine. 
TABLE I. PARAMETERS OF THE ORIGINAL Y4100ZL DIESEL ENGINE

\begin{tabular}{c|c}
\hline Model number & Y4100zl \\
\hline Type & $\begin{array}{c}\text { Upright, Inline,4 cyliner, hydro cooling, 4 } \\
\text { stroke }\end{array}$ \\
\hline diameter $\times$ stroke & $100 \mathrm{~mm} \times 105 \mathrm{~mm}$ \\
\hline Displacement $(\mathrm{L})$ & 3.298 \\
\hline Rated power/speed & $84 \mathrm{~kW} / 3000\left(\mathrm{r} \cdot \mathrm{min}^{-1}\right)$ \\
\hline Rated torque/speed & $307 \mathrm{Nm} / 2100\left(\mathrm{r} \cdot \mathrm{min}^{-1}\right)$ \\
\hline Intake mode & Turbo charge, intercool \\
\hline turbocharger & RHB5 \\
\hline Fuel supply & PM pump,$\Phi 10.5 \mathrm{~mm}$ \\
\hline Compression ratio & 19.9 \\
\hline $\begin{array}{c}\text { Shape of combustion } \\
\text { chamber }\end{array}$ & Dump-bell shaped \\
\hline Injector & $6-21-152$ \\
\hline
\end{tabular}

\section{EXPERIMENTAL RESULTS AND ANALYSIS}

The main idea of this paper is to achieve low explosion pressure combustion on the premise of power performance not changed, so to reduce the risk of reliability, but the rapid combustion is still able to be achieved, the fuel consumption rate does not deteriorate, and the goal of low emissions can also be achieved.

Figure 2 shows the external characteristic torque curve of the original engine.

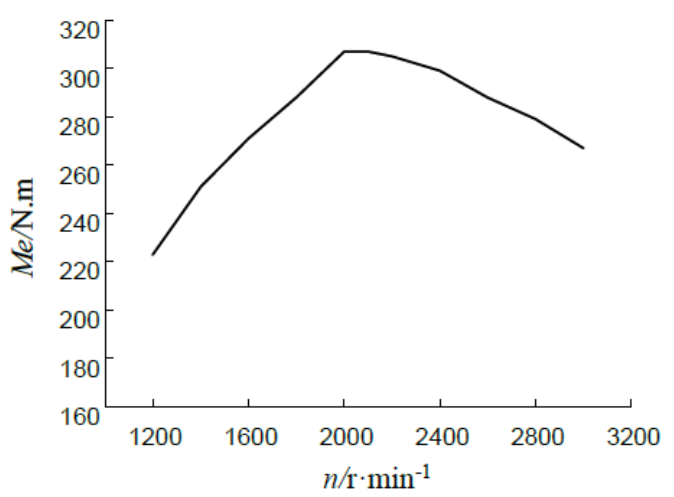

FIGURE II.

EXTERNAL CHARACTERISTIC TORQUE CURVE OF THE ORIGINAL ENGINE

\section{A. Double Wall Jet Combustion Heat Release Rate}

Figure 3 shows the instantaneous heat release rate of different load each at low-speed $\left(1400 \mathrm{r} \bullet \mathrm{min}^{-1}\right)$, medium-speed $\left(2100 \mathrm{r} \cdot \mathrm{min}^{-1}\right)$ and rated speed $\left(3000 \mathrm{r} \cdot \mathrm{min}^{-1}\right)$. It can be seen from the figure that heat release rate of many conditions has a single peak trend, that's because: The combustion at low-speed (medium and high load) and medium-speed (medium load) is premix combustion and has high combustion rate; The combustion at high-speed (high load) is diffusion combustion, but for the rapid-mixing characteristics of the double-wall-jet combustion system, the diffusion combustion is part of advanced, so the combustion duration is shortened, rapid combustion is achieved. The problem of peak heat release rate should be determined based on the amount of premixed combustion and diffusion combustion.

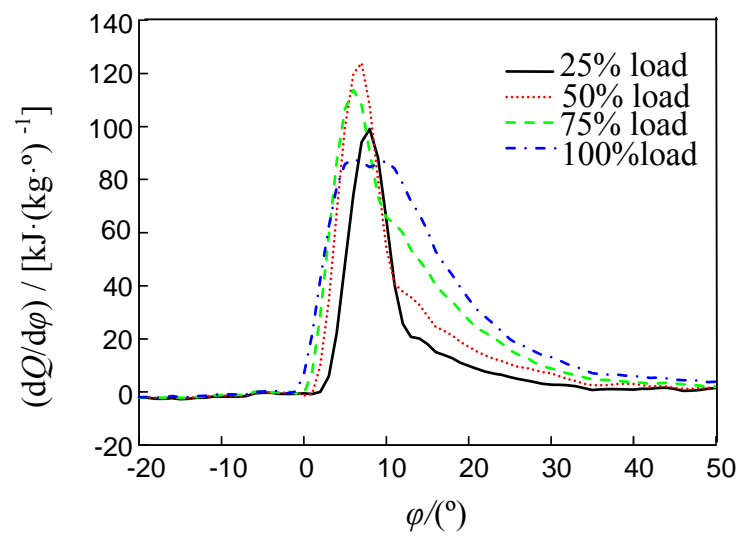

(a) $1400 \mathrm{r} \cdot \mathrm{min}^{-1}$

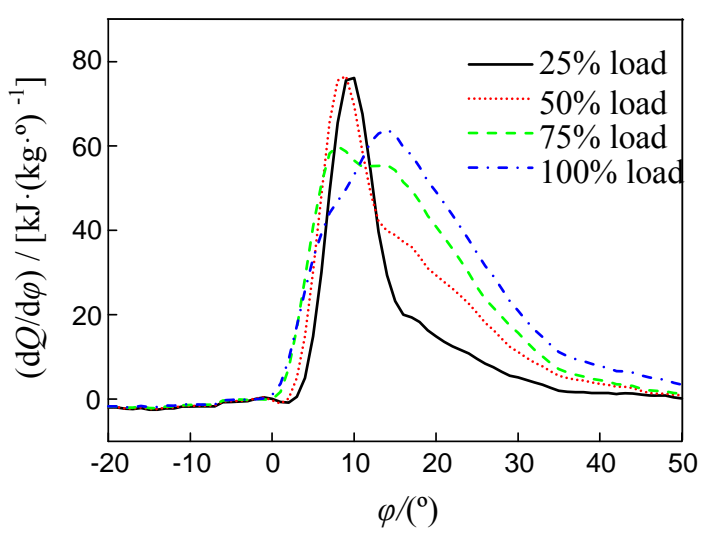

(b) $2100 \mathrm{r} \cdot \mathrm{min}^{-1}$ 


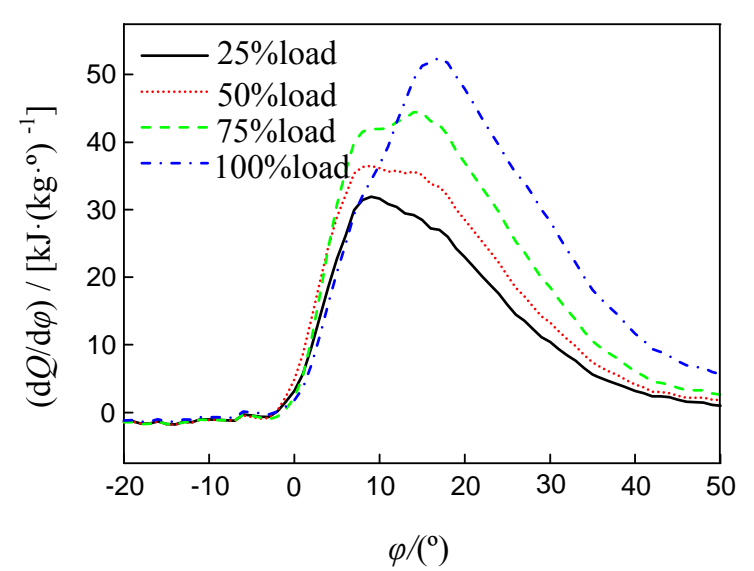

(c) $3000 \mathrm{r} \cdot \mathrm{min}^{-1}$

\section{FIGURE III. INSTANTANEOUS HEAT RELEASE RATE OF DOUBLE-WALL-JET DIESEL ENGINE AT DIFFERENT SPEED}

\section{B. Low Explosion Pressure Characteristics of Double-Wall- Jet Combustion System}

Figure 4 shows the comparison of cylinder pressure between the double-wall-jet engine and the original engine at $2100 \mathrm{r} \cdot \mathrm{min}-1.25 \%$ load of the double-wall-jet engine is expressed as "S 25\% load", 25\% load of the original engine is expressed as "Y 25\% load", the express method of other load is same. It can be seen from the figure that the double-wall-jet combustion system has low explosion pressure, which ensures the reliability of the engine components, that's mainly because the double-wall-jet combustion system has a lower geometric compression ratio $(\varepsilon=16.5)$. The reduced compression ratio reduces the pressure of at the end of compression, the ignition point is postponed for $3 \sim 4^{\circ} \mathrm{CA}$, the delay period is longer, the proportion of premixed combustion is increased. Figure 5 (b) shows that the peak cylinder pressure of the double-wall-jet engine respectively decreases $20.1 \%$ (25\% load), $16.9 \%(50 \%$ load), $17.7 \%$ (75\% load) and $23.5 \%$ (100\% load) compared with that of the original engine.

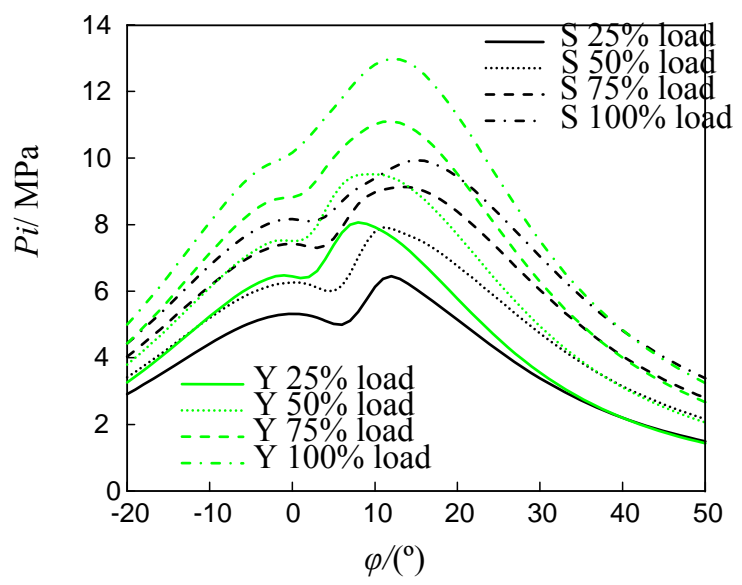

(a) comparison of cylinder pressure

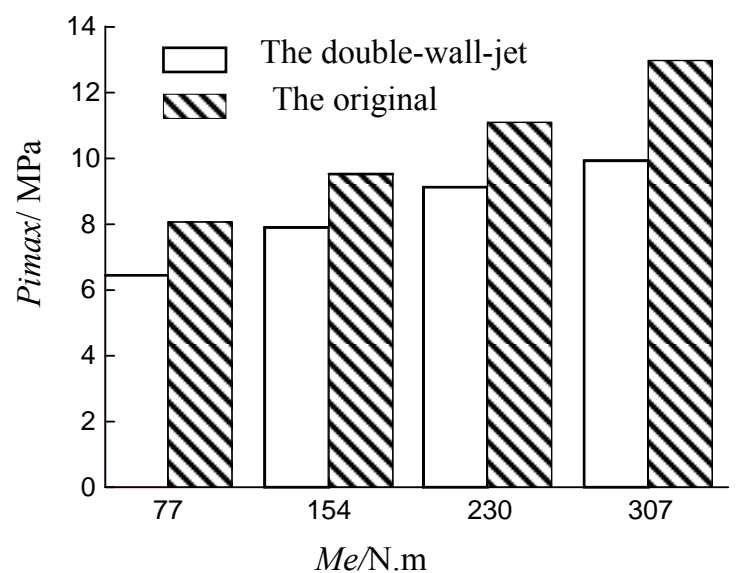

(b) comparison of peak cylinder pressure

FIGURE IV. COMPARISON OF CYLINDER PRESSURE BETWEEN THE DOUBLE-WALL-JET ENGINE AND THE ORIGINAL ENGINE AT 2100R.MIN ${ }^{-1}$

Figure 5 shows the comparison of $\mathrm{P}-\mathrm{V}$ diagram between the double-wall-jet engine and the original engine. Compared with the original engine, the pressure of the double-wall-jet engine is lower around TDC and is higher in other domain, the difference of the surrounded area is very little, so the indicated power is not decreased.

Figure 6 shows the comparison of average cylinder temperature between the double-wall-jet engine and the original engine at $2100 \mathrm{r} \bullet \mathrm{min}^{-1}$. It can be seen from the figure that the cylinder pressure of the double-wall-jet engine is lower, the ignition point is postponed, so the cylinder temperature is also decreased. Figure 6 (b) shows that the peak average cylinder temperature of the double-wall-jet engine respectively is $1349 \mathrm{~K}(25 \%$ load $), 1511 \mathrm{~K}(50 \%$ load $), 1650 \mathrm{~K}(75 \%$ load $)$ and $1706 \mathrm{~K}(100 \%$ load $)$.

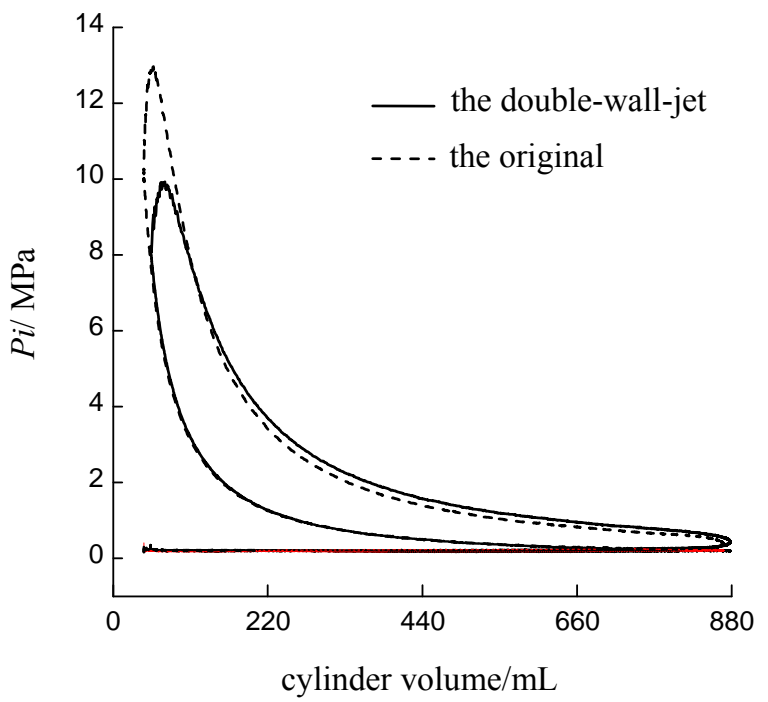

FIGURE V. COMPARISON OF P-V BETWEEN THE DOUBLEWALL-JET ENGINE AND THE ORIGINAL ENGINE AT 2100R.MIN 
1/307N.M (100\% LOAD)

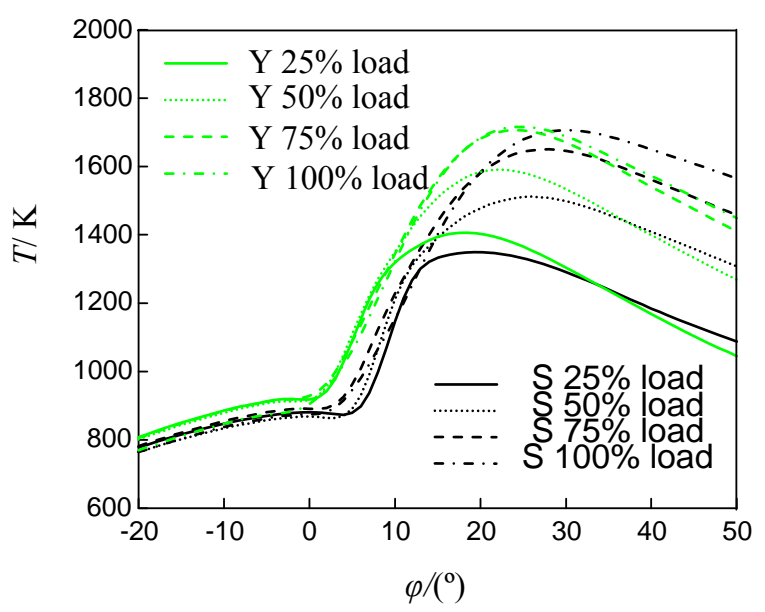

(a) comparison of average cylinder temperature

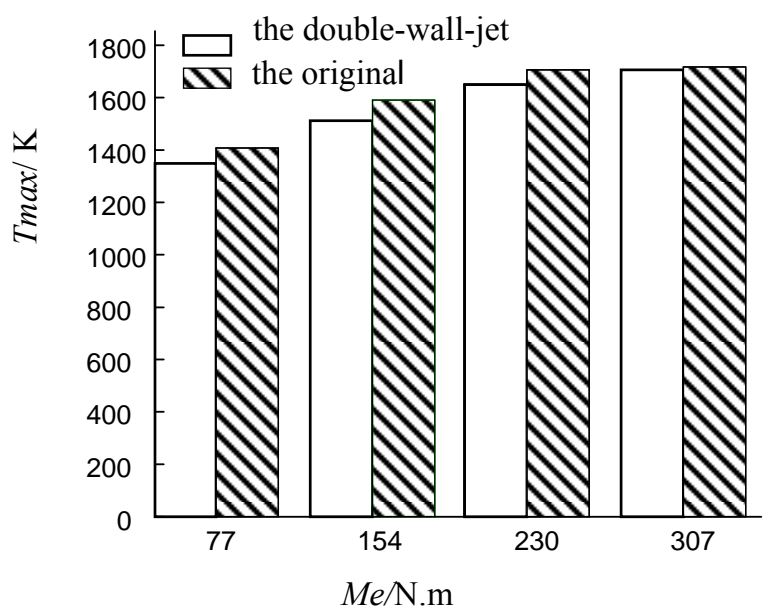

(b) comparison of peak average cylinder temperature

FIGURE VI. COMPARISON OF AVERAGE CYLINDER TEMPERATURE BETWEEN THE DOUBLE-WALL-JET ENGINE AND THE ORIGINAL ENGINE AT 2100R.MIN ${ }^{-1}$

The cylinder temperature is decreased, so the NOx emission is decreased as shown in Figure 7 (b). The soot emission is slightly increased, that's because: The original engine has a higher compression ratio, so the oxidation of soot in late combustion is enhanced; for the double-wall-jet engine, the oxidation of soot is weakened with the piston downward (the combustion temperature decreases) and the film on the chamber wall can not be quickly evaporated, so more soot is produced. Figure 8 (a) shows that the fuel consumption rate of the double-wall-jet engine (the compression ratio is lower) is almost same as that of original engine (the compression ratio is higher).

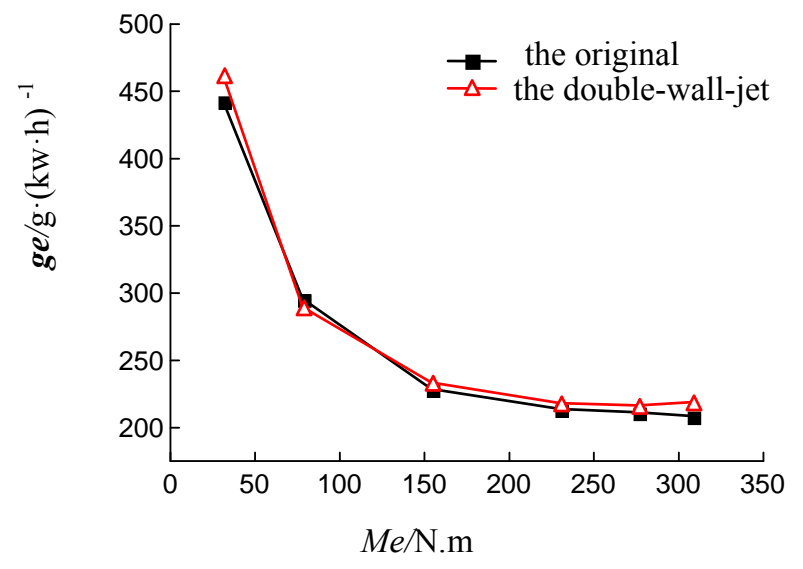

(a) comparison of fuel consumption rate

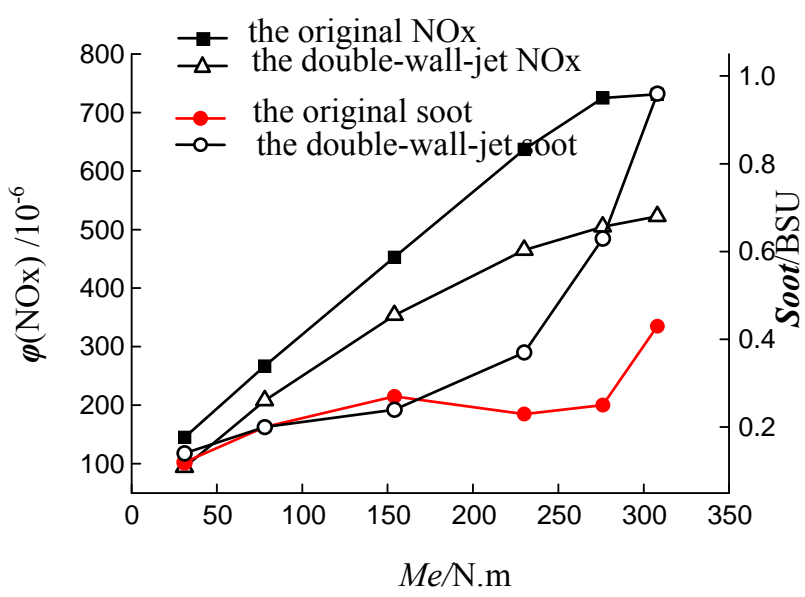

(b) comparison of NOx and soot

FIGURE VII.

COMPARISON OF GE, NOX AND SOOT BETWEEN THE DOUBLE-WALL-JET ENGINE AND THE ORIGINAL ENGINE AT 2100R.MIN ${ }^{-1}$

\section{Analysis of Fuel Consumption Rate for the Double-Wall- Jet Combustion System \\ 1) Cumulative heat release rate $Q$}

Figure 8 shows the comparison of the cumulative heat release rate between the double-wall-jet engine and the original engine at $2100 \mathrm{r} \bullet \mathrm{min}^{-1}$. It can be seen from the figure that the ignition point of the double-wall-jet combustion system is postponed for about $3^{\circ} \mathrm{CA}$.

\section{2) Percentage of cumulative heat release}

Figure 9 shows the crank angle corresponding with the cumulative heat release of the double-wall-jet engine and the original engine at 2100r.min ${ }^{-1}$. The crank angles corresponding with $10 \%, 30 \%, 50 \%, 70 \%$ and $90 \%$ cumulative heat release are respectively expressed as $\theta 10, \theta 30, \theta 50, \theta 70$ and $\theta 90, \theta 0$ represents the starting point.

It can be seen from Figure 8 or Figure 9 that: 
$25 \%$ load: $\theta 50-\theta 0$ of the double-wall-jet engine is less than that of the original engine; $\theta 70-\theta 0$ of the double-wall-jet engine is almost the same as that of the original engine, and the combustion becomes very slow when the cumulative heat release is more than $70 \%$.

$50 \%$ load: $\theta 30-\theta 0$ of the double-wall-jet engine is less than that of the original engine; $\theta 50-\theta 0$ of the double-wall-jet engine is same as that of the original engine.

$75 \%$ load: $\theta 30-\theta 0$ of the double-wall-jet engine is same as that of the original engine.

$100 \%$ load: combustion rate of the double-wall-jet engine is lower than that of the original engine.

It can be seen that the initial combustion rate of the doublewall-jet engine is very high, but becomes slow with the combustion continuing. This is mainly due to the pure premix combustion at small load and rapid-mixing characteristics of the double-wall-jet combustion system. The cylinder volume of the double-wall-jet engine is bigger than that of the original engine, and the ignition point is postponed, so the cylinder temperature of the double-wall-jet engine is lower, the combustion rate is reduced. As the load increases, the duration of fuel injection is extended, the injected fuel increases, the oil film on the wall increases and can not absorb enough heat to evaporate quickly, which also leads to the combustion rate reduced.

\section{3) Indicated thermal efficiency}

Indicated thermal efficiency is divided into total indicated thermal efficiency and pure indicated thermal efficiency.

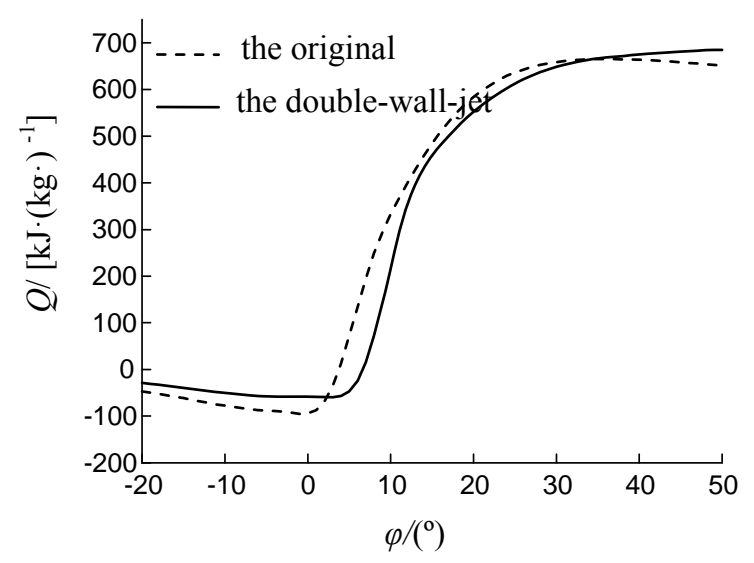

(a) $25 \%$ load

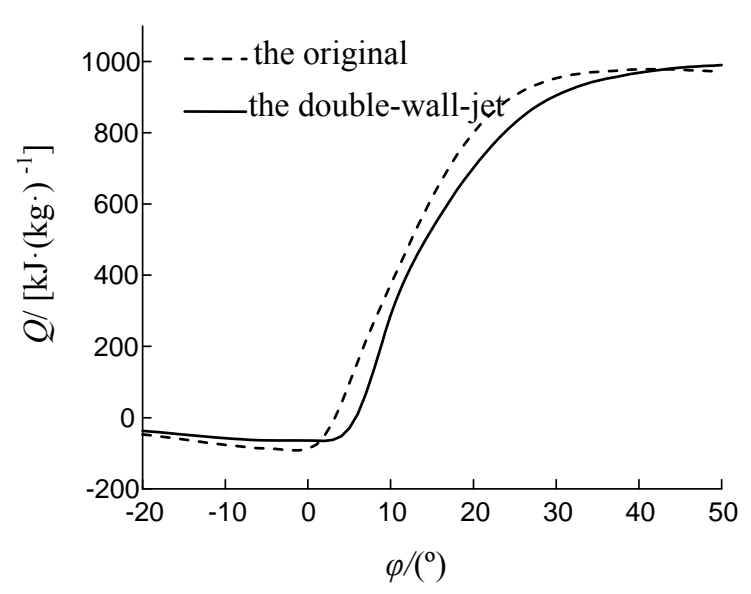

(b) $50 \%$ load

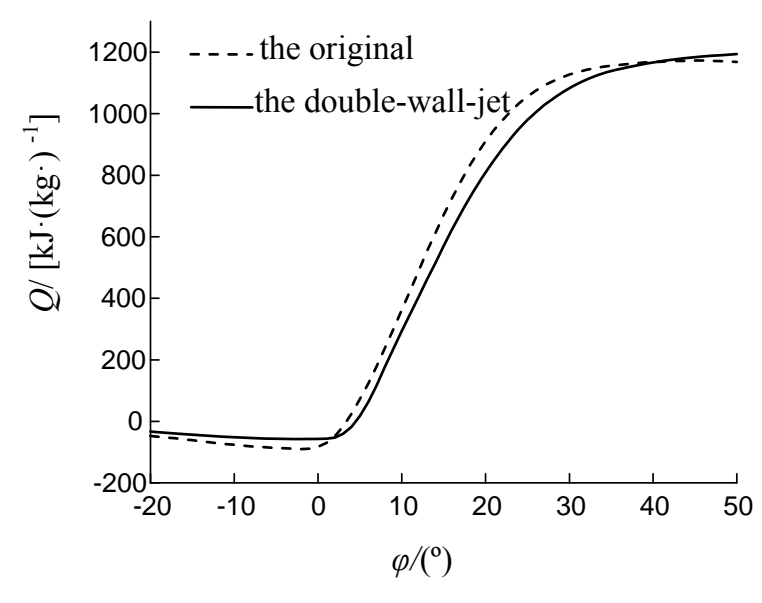

(c) $75 \%$ load

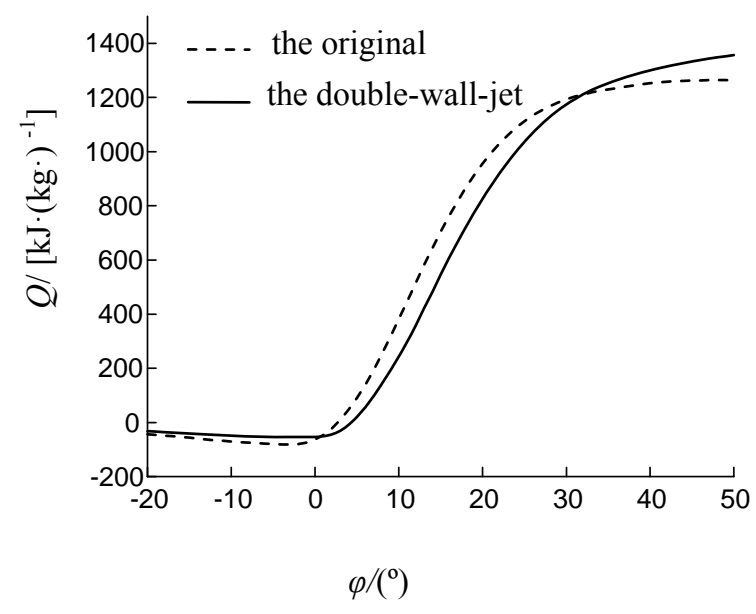

(d) $100 \%$ load

FIGURE VIII. COMPARISON OF THE CUMULATIVE HEAT RELEASE RATE BETWEEN THE DOUBLE-WALL-JET ENGINE AND THE ORIGINAL ENGINE AT 2100R.MIN ${ }^{-1}$ 


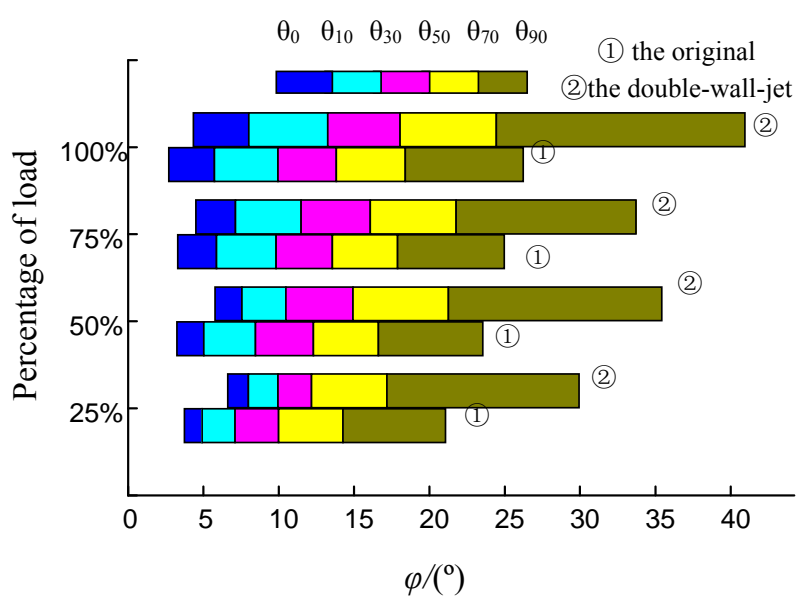

FIGURE IX. THE CRANK ANGLE CORRESPONDING WITH THE CUMULATIVE HEAT RELEASE OF THE DOUBLE-WALL-JET ENGINE AND THE ORIGINAL ENGINE AT 2100R.MIN ${ }^{-1}$

Figure 10 shows the comparison of total indicated thermal efficiency and pure indicated thermal efficiency between the double-wall-jet engine and the original engine at $2100 \mathrm{r} \cdot \mathrm{min}^{-1}$.

When the load increases, the combustion rate in the postcombustion is reduced, energy efficiency is relatively worse, so the indicated thermal efficiency of the double-wall-jet engine is lower than that of the original engine in large load.

\section{4) Single peak heat release rate}

It can be seen form Figure 3 that the double-wall-jet combustion system shows a feature of single peak heat release rate in a number of conditions which has been explained before.

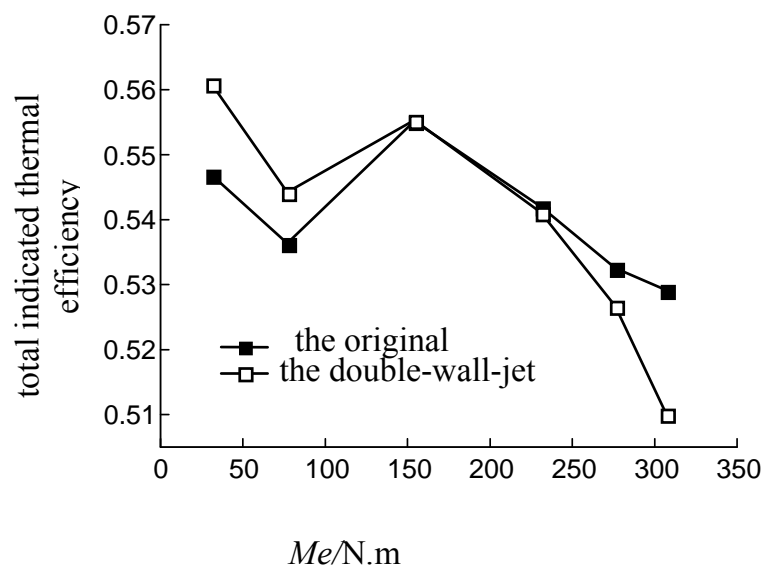

(a) total indicated thermal efficiency

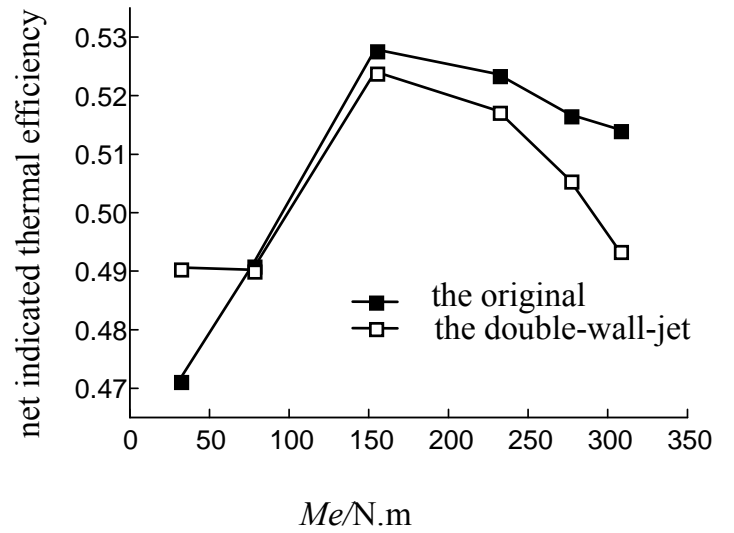

(b) pure indicated thermal efficiency

FIGURE $X$ COMPARISON OF THE INDICATED THERMAL EFFICIENCY BETWEEN THE DOUBLE-WALL-JET ENGINE AND THE ORIGINAL ENGINE AT 2100R.MIN ${ }^{-1}$

\section{CONCLUSION}

(1) According to the spray characteristics and formation mechanism of NOx and soot of DI engine, a double-wall-jet combustion system is designed. The double-wall-jet combustion system has lower geometric compression ratio and single peak heat release rate characteristics.

(2) The low-compression-ratio double-wall-jet combustion system achieves low explosion pressure, low combustion temperature and low NOx emission without power performance not reduced.

(3) The low-explosion combustion is achieved; the fuel consumption rate is analyzed based on such parameters as cumulative heat release rate, percentage of total heat release, a single peak heat release rate and the indicated thermal efficiency.

\section{REFERENCE}

[1] Adam E. Klingbeil, Harmit Juneja, Youngchul Ra,et al.Premixed Diesel Combustion Analysis in a Heavy-Duty Diesel Engine[R]. SAE Paper,No2003-01-0341,2003

[2] Naoya Ishikawa, Taiji Uekusa and Teruo Nakada. DI Diesel Emission Control by Optimized Fuel Injection[R]. SAE Paper,No2004-010117,2004

[3] kaneko tomomi, kikuta kazuige, chikahisa takemi. Research about effect of local diffusive structure on emission of NOx and method of decreasing emissions for diesel engine $[\mathrm{J}]$. foreign internal combustion engine,2007,(3),41-45.

[4] Yoshinori Iwabuchi, Kenji Kawai, Takeshi Shoji ,et al. Trial of New Concept Diesel Combustion System Premixed Compression Ignited Combustion[R]. SAE Paper,No1999-01-0185,1999 